\title{
Comparative study of causative organism in erosive cervicitis, cervical intra epithelial neoplasia and carcinoma cervix using Pap smear
}

\author{
Jyoti Bindal, Deepak Paldiya*
}

Department of Obstetrics and Gynecology, G. R. Medical College, Gwalior, Madhya Pradesh, India

Received: 09 June 2017

Revision: 23 August 2018

Accepted: 28 August 2018

\author{
*Correspondence: \\ Dr. Deepak Paldiya, \\ E-mail: paldiyadeepak@gmail.com
}

Copyright: (c) the author(s), publisher and licensee Medip Academy. This is an open-access article distributed under the terms of the Creative Commons Attribution Non-Commercial License, which permits unrestricted non-commercial use, distribution, and reproduction in any medium, provided the original work is properly cited.

\begin{abstract}
Background: Cervical cancer is the third largest cause of cancer mortality in India after cancers of the mouth and oropharynx, and oesophagus, accounting for nearly $10 \%$ of all cancer related deaths in the country.

Methods: The present study carried out 300 patients in Gajra Raja Medical College in the Department of Obstetrics and Gynaecology, OPD and indoor admitted patients from July 2016 to December. 2016. The selected patients were examined with care to note any cervical lesion, appearance of cervix, nature of any cervical/vaginal discharge. Then a cervical scrape was taken with an Ayre's spatula and slide stained and then examined.

Results: The maximum cases of HPV were seen in CIN, LSIL and HSIL. Maximum incidence of all cases was seen in the age group of 30-50 yrs. The women married before 18 years had the highest incidence of CIN and HPV infection. Majority of the cases of cervicitis were co-infected with $\mathrm{H}-$ Vaginalis and Trichomonas. Most women opted for a sterilization procedure rather than any other method of contraception. Use of no contraception puts these women at a high risk of acquiring HPV infection from infected partners.

Conclusions: Occurrence of HPV infection declines with increasing grades. Most of the patients with HPV infection had presented with non-specific symptoms of discharge P/V or lower abdominal pain.
\end{abstract}

Keywords: Cervical cancer, CIN, HPV infection

\section{INTRODUCTION}

Cervical cancer is the third largest cause of cancer mortality in India after cancers of the mouth and oropharynx, and oesophagus, accounting for nearly $10 \%$ of all cancer related deaths in the country. Among women, it is the leading cause of cancer mortality, accounting for $26 \%$ of all cancer deaths. According to International agency for research in cancer estimates, mortality from cervical cancer is expected to witness a $79 \%$ increase from 74,118 deaths in 2002 to 132,745 deaths by $2025 .^{1}$

It is estimated that in India, 1,26,000 new cases occur each year. ${ }^{2}$ The incidence of cervical cancer has decreased by more than $50 \%$ in the past $30+$ years, due to the increasing use of cervical cancer screening with cervical cytology. ${ }^{3}$ The mainstay of cervical cancer screening has been the Papanicolaou test, also known as the Pap test or the Pap smear. It was developed by Dr. George Papanicolaou in the 1940s who discovered that precancerous and cancerous cells could be identified in cytologic samples from vaginal aspirates. ${ }^{4}$ Unlike most other malignancies, cancer of cervix is readily preventable when effective programmes are conducted to detect and treat its precursor lesions. ${ }^{2}$

This disease has a natural history where the malignant epithelial transformation evolves over many years from carcinoma-in-situ to frankly invasive lesions. The 
anatomical accessibility of the cervix to physical examination the disease can be detected at an early stage, when definite cure is readily achieved by surgery or radiotherapy.

\section{METHODS}

The present study carried out 300 patients in Gajra Raja Medical College in the Department of Obstetrics and Gynaecology, OPD and indoor admitted patients from July 2016 to December 2016.

These patients were analyzed through a thorough history taking with special emphasis on risk factors for HPV infection and thus carcinoma cervix. Then the selected patients were examined with care to note any cervical lesion, appearance of cervix, nature of any cervical/ vaginal discharge.

Then a cervical scrape was taken with an Ayre's spatula and slide stained and then examined. Method of smear preparation and slide staining. Two techniques have been used - aspiration from post fornix, originally introduced by Papanicolaou and Cervical scrape method.

\section{RESULTS}

Of the 300 patients studied, 158 of the patients $(52.5 \%)$ studied, had some degree of dysplasia, delineating a big group of patients with CIN, who if timely treated, could be prevented from developing cervical malignancy. 126 (42\%) had erosive cervicitis and $18(5.5 \%)$ had cervical carcinoma (Table 1). Nearly 50 percent of the patients had the evidence of HPV infection on Pap smear, showing the high prevalence of HPV infection in women attending the gynecology OPD (Table 2).
Table 1: Diagnosis wise distribution of cases.

\begin{tabular}{|l|l|}
\hline Diagnosis & Cases \\
\hline Total cases & 300 \\
\hline Cervicitis & $126(42 \%)$ \\
\hline CIN & $158(52.5 \%)$ \\
\hline LSIL & $101(64.76 \%)$ \\
\hline HSIL & $55(44.76 \%)$ \\
\hline Carcinoma cervix & $7(5.5 \%)$ \\
\hline
\end{tabular}

Table 2: Cases with HPV changes on cytology.

\begin{tabular}{|l|l|}
\hline Total cases & Cases with HPV changes \\
\hline 300 & $138(46 \%)$ \\
\hline
\end{tabular}

The maximum cases of HPV were seen in CIN. As can be seen from the table, the occurrence of HPV infection declines with increasing grades (Table 3). Maximum incidence of all cases was seen in the age group of 30-50 years (Table 4). The age distribution pattern shows that women with at least three or more children are the most sufferers from both CIN and Carcinoma cervix (Table 5).

Table 3: Case wise HPV changes on cytology.

\begin{tabular}{|l|l|}
\hline Diagnosis & No. Of cases with changes of \\
\hline Overall & $138 / 300(46 \%)$ \\
\hline Cervicitis & $51 / 126(40.47 \%)$ \\
\hline CIN & $68 / 158(42.85 \%)$ \\
\hline LSIL & $48 / 101(47.05 \%)$ \\
\hline HSIL-Mod Dyspl & $19 / 36(54.16 \%)$ \\
\hline HSIL-Sev Dyspl & $0 / 19(0 \%)$ \\
\hline Carcinoma & $0 / 17(0 \%)$ \\
\hline
\end{tabular}

Table 4: Age wise distribution of HPV positive cases by cytology.

\begin{tabular}{|l|l|l|l|l|l|l|}
\hline Cases & $\mathbf{1 0 - 1 9}$ & $\mathbf{2 0}-\mathbf{2 9}$ & $\mathbf{3 0 - 3 9}$ & $\mathbf{4 0 - 4 9}$ & $\mathbf{5 0 - 5 9}$ & $>\mathbf{6 0}$ years \\
\hline Overall & $06(4.34 \%)$ & $31(22.82 \%)$ & $46(32.6 \%)$ & $42(30.43 \%)$ & $09(6.52 \%)$ & $04(3.26 \%)$ \\
\hline Cervicitis & 05 & 17 & 19 & 07 & 02 & 02 \\
\hline CIN & 01 & 10 & 21 & 28 & 08 & 03 \\
\hline LSIL & 01 & 08 & 20 & 21 & 03 & 01 \\
\hline HSIL-Mod Dyspl & - & 03 & 02 & 06 & 06 & 01 \\
\hline HSIL-Severe Dyspl & - & - & - & - & - & - \\
\hline Carcinoma & - & - & - & - & - & - \\
\hline
\end{tabular}

Table 5: Parity wise distribution of cases.

\begin{tabular}{|l|l|l|l|l|l|l|l|l|l|}
\hline Cases & P0 & P 1 & P 2 & P 3 & P 4 & P 5 & P6 & P7 \\
\hline Overall & $18(6 \%)$ & $27(9 \%)$ & $56(18.5 \%)$ & $78(26 \%)$ & $55(18.5 \%)$ & $40(13.5 \%)$ & $18(6 \%)$ & $08(2.5 \%)$ \\
\hline Cervicitis & 11 & 17 & 20 & 29 & 17 & 08 & 02 & 03 \\
\hline CIN & 04 & 09 & 25 & 35 & 27 & 24 & 10 & 03 \\
\hline LSIL & 02 & 03 & 16 & 33 & 15 & 15 & 06 & 01 \\
\hline HSIL-Mod Dyspl & 03 & 06 & 06 & 07 & 07 & 05 & 03 & 01 \\
\hline HSIL-Severe Dyspl & - & - & 01 & 04 & 05 & 03 & 03 & - \\
\hline Carcinoma & - & - & - & 04 & 04 & 03 & 02 & 01 \\
\hline
\end{tabular}


Overall, most women were married at an early age. The women married before 18 years form a huge group, and these women had the highest incidence of CIN and HPV infection (Table 6).

Majority of the cases of cervicitis were co-infected with $\mathrm{H}-$ Vaginalis and Trichomonas (Table 7). As seen from above table, most women opted for a sterilization procedure rather than any other method of contraception. Use of no contraception puts these women at a high risk of acquiring HPV infection from infected partners (Table 8).
Table 6: Age at marriage /first intercourse of HPV positive cases.

\begin{tabular}{|l|l|l|l|l|}
\hline Cases & $<12$ & $\mathbf{1 3 - 1 8}$ & $\begin{array}{l}19-25 \\
\text { years }\end{array}$ & $\begin{array}{l}>25 \\
\text { years }\end{array}$ \\
\hline Overall & 48 & 60 & 30 & years \\
\hline Cervicitis & 13 & 21 & 16 & 0 \\
\hline CIN & 29 & 31 & 11 & 0 \\
\hline LSIL & 22 & 24 & 08 & 0 \\
\hline HSIL & 06 & 07 & 04 & 0 \\
\hline
\end{tabular}

Table 7: Co-infection in cases with HPV infection.

\begin{tabular}{|c|c|c|c|c|c|}
\hline Cases & Candida & H. vaginalis & Trichomonas & Other & Total \\
\hline Overall & $12(8.7 \%)$ & $39(28.26 \%)$ & $35(25 \%)$ & - & $86(61.97 \%)$ \\
\hline Cervicitis & 06 & 18 & 17 & - & $45(32.8 \%)$ \\
\hline CIN & 04 & 18 & 15 & - & $40(29.34 \%)$ \\
\hline LSIL & 02 & 10 & 05 & 1-Chalmydia & $19(14.13 \%)$ \\
\hline HSIL & 03 & 06 & 09 & - & $21(15.21 \%)$ \\
\hline Carcinoma & - & - & - & - & - \\
\hline
\end{tabular}

Table 8: Contraceptive practice in relation to HPV infection.

\begin{tabular}{|l|l|l|l|l|}
\hline Cases & Oral contraceptives & Barrier methods & Sterilization procedures & None \\
\hline Overall & $07(5.43 \%)$ & $06(4.34 \%)$ & $70(51.08 \%)$ & $33(23.91 \%)$ \\
\hline Cervicitis & 02 & 01 & 16 & 15 \\
\hline CIN & 04 & 04 & 45 & 14 \\
\hline LSIL & 03 & 04 & 30 & 08 \\
\hline HSIL & 01 & - & 14 & 05 \\
\hline
\end{tabular}

\section{DISCUSSION}

The present study is entitled Comparative study of causative organism in cervicitis, cervical intra epithelial neoplasia, and carcinoma cervix, using Pap smear. 158 patients had dysplasia of various grades and 11 patients had carcinoma cervix. The high incidence of dysplasia among these patients was because only high-risk patients had been taken into this study. Among these 158 patients, $101(64.68 \%)$ had LSIL and 55 patients (35.32\%) had HSIL. Mohini Garud et al in their study they found $63.2 \%$ had mild dysplasia, $23.3 \%$ had moderate dysplasia and $13.8 \%$ severe dysplasia. ${ }^{5}$

The average age of incidence of any of the cervical lesions was maximum in the age group $30-50$ years. This outcome corresponds to age incidence of dysplasia found in similar studies done previously correlated with Mohini Garud et al (20-40 years). ${ }^{5} 8$ out of 17 cases of carcinoma were seen in women between 30-50 years and above. This finding is consistent with current world trends in age- specific cancer incidence as seen from the study done by Parkin DM et al in 2002. ${ }^{6} 72.38 \%$ of the cases of dysplasia were found in women with parity 3 or more.
This is especially true in cases of HSIL. With increasing parity, more women had higher-grade lesions. All the 17 cases of carcinoma cervix were found in women with three or more children $(100 \%)$. This finding is similar as that of Jito Mohanty et al in their study on invasive carcinoma, where they found a $93 \%$ assosciation with multiparity. ${ }^{7}$

HPV infection shows a similar relationship to high parity. $82.6 \%$ patients with HPV infection were of parity 3 or greater. This finding is consistent with the risk that multiple births imply recurrent damage and infection of the cervix. Other study showed that cervical cancer risk rose steadily as a woman's number of birds increased. ${ }^{8}$

In present study, $74 \%$ of these women with HPV either had undergone a permanent procedure or used no contraceptive method. In present study percentage of OCP and HPV were $5.43 \%$. The study done in this regard by Paba $\mathrm{B}$ et al showed no association between OCP usage and occurrence or progress of HPV infection and SIL of cervix. ${ }^{9}$ Of the 92 women with HPV infection, $35 \%$ had been married before the age of 12 years while $43 \%$ were married before the age of 18 years. All the 17 
patients with carcinoma had been married before the age of 12 years. In other study done by Africa SS, cervical cancer closely liked with the age at first birth. ${ }^{8}$ Most commonly seen was $H$. vaginalis $(28.3 \%)$ followed by Trichomonas infection (23\%) and Candida (8\%). Coinfection has been found to increase the occurrence of dysplasia. Study done by Kone ES et al, they found candida seen in $57.78 \%$ and trichomas $50 \%$ which is not correlated with present study. ${ }^{10}$ The analysis of symptoms also showed that most of these women had been suffering from these symptoms for quite a long period. Most of them, being homemakers, were given least attention by the family members. Lack of knowledge coupled with lack of facility and money forced many of these women to suffer long from the symptoms until they were sick enough for urgent medical attention. Of the eleven cases of carcinoma cervix, only three were in stage 2 . Rest of them was sadly, inoperable.

\section{CONCLUSION}

Most women at the OPD have one or the other risk factors for cervical disease. Majority of these affected patients with erosive cervicitis and dysplsia with HPV had mild or moderate dysplsia. Occurrence of HPV infection declines with increasing grades. Most of the patients with HPV infection had presented with nonspecific symptoms of discharge P/V or lower abdominal pain. All these women should be advised follow-up and its importance. All women who have cytological abnormalities or high-risk factors need to undergo a HPV DNA typing study.

Funding: No funding sources Conflict of interest: None declared

Ethical approval: The study was approved by the Institutional Ethics Committee

\section{REFERENCES}

1. Parimala A, Sharma N, Srinivasan JK. Screening of cancer cervix: Paper smear in rural India. Int $\mathbf{J}$ Reprod Contracept Obstet Gynecol. 2016;5(7):21135 .
2. Bal MS, Goyal R, Suri AK, Mohi MK. Detection of abnormal cervical cytology in Papanicolaou smears. J Cytol. 2012;29(1):45-7.

3. American College of Obstetricians and Gynaecolgists. Cervical cancer screening and prevention. Practice Bulletin No. 157. Obstet Gynecol. 2016;127(1):1-20.

4. Gibb RK, Martens MG. The impact of liquid based cytology in decreasing the incidence of cervical cancer. Rev Obstet Gynecol. 2011;4(1):S2-11.

5. Saraiya U, Gupta PC, Lulla M, Garud M. Formulation of a scoring system based on disicriminant analysis of risk factors in development of cervical cancer-a comparative study of cases of cancer, dysplasia and control group. $26^{\text {th }}$ Conference of Federation of Obstetrics and Gynaecology Societies of India; 1983:508-511.

6. Parkin DM. The global health burden of infectionassociated cancers in the year 2002. Int J Cancer. 2006;118(12):3030-44.

7. Mohanty J, Mohanty BK. J Obstet Gynecol India.1991;41(3):403-6.

8. Africa SS. Long term pill use, high parity raise cervical cancer risk among women with human papillomavirus infection. International Perspective on sexual and reproductive health. A J Peer-reviewed Res 2002;28(3):176-177.

9. Paba P, Bonifacio D, Di Bonito L, Ombres D, Favalli C, Syrjanen K, et al. Co-expression of HSV2 and Chlamydia trachomatis in HPV-positive cervical cancer and cervical intraepithelial neoplasia lesions is associated with aberrations in key intracellular pathways. Intervirol. 2008;51(4):230-4.

10. Kone ES, Balilli AD, Paparisto PD, Ceka XR, Petrela ED. Vaginal infection of Albanian women infected with HPV and their impact in intraepithelial cervical lesions evidenced by Pap test. J Cytol 2017;34(1):16-21.

Cite this article as: Bindal J, Paldiya D.

Comparative study of causative organism in erosive cervicitis, cervical intra epithelial neoplasia and carcinoma cervix using Pap smear. Int J Reprod Contracept Obstet Gynecol 2019;8:1186-9. 